\title{
Evaluation of an improved micro milling strategy for the generation of tool steel micro features with optical functionality
}

Li, D.; Davoudinejad, A.; Zhang, Y.; Tosello, G.

Publication date:

2018

Document Version

Publisher's PDF, also known as Version of record

Link back to DTU Orbit

Citation (APA):

Li, D., Davoudinejad, A., Zhang, Y., \& Tosello, G. (2018). Evaluation of an improved micro milling strategy for the generation of tool steel micro features with optical functionality. Paper presented at 2018 World Congress on Micro and Nano Manufacturing (WCMNM2018), Portorož, Slovenia.

\section{General rights}

Copyright and moral rights for the publications made accessible in the public portal are retained by the authors and/or other copyright owners and it is a condition of accessing publications that users recognise and abide by the legal requirements associated with these rights.

- Users may download and print one copy of any publication from the public portal for the purpose of private study or research.

- You may not further distribute the material or use it for any profit-making activity or commercial gain

- You may freely distribute the URL identifying the publication in the public portal 


\title{
Evaluation of an improved micro milling strategy for the generation of tool steel micro features with optical functionality

\author{
D. Li ${ }^{1}$, A. Davoudinejad ${ }^{1}$, Y. Zhang ${ }^{1}$, G. Tosello ${ }^{1}$
}

${ }^{1}$ Technical University of Denmark, Department of Mechanical Engineering, DK-2800 Kgs. Lyngby, Denmark

\begin{abstract}
This paper discusses a new micro milling strategy for manufacturing optical functionality on steel. The microstructures, a combination of arrays of micro-ridges, has been developed to achieve the function. The function is to maximize the contrast of the reflected light from orthogonally patterned features. The burr formation and insufficient material removal, influenced by the tool wear and the machine accuracy, were the main challenges in this process. The cutting strategy was investigated in order to reduce the burr formation during the process. By the new strategy, the ridge machining order was reversed. The evaluation of the feature geometries proved that new strategy could improve the feature quality. The ultimate goal was to improve the surface functionality.
\end{abstract}

Keywords: functional surfaces, micro structures, micro milling strategy.

\section{Introduction}

Functional surfaces are under intensive investigations thanks to the applications at industrial and commercial level. Extensive studies on their application and manufacturing processes have been performed $[1,2]$. The present paper explored a new micro milling strategy to manufacture micro-structured surfaces with a novel optical function on the injection moulding inserts for replication.

The surface functionality to be achieved is, under a fixed light source, the maximization of the reflectance from a certain angle and direction, and the minimization from its horizontally orthogonal position.

As is shown in Fig. 1, the functional surface was structured with serrated ridges. These structures led to different intensities of the reflected light according to the surface rotation around the $Z$ axis by $90^{\circ}$. The difference between reflected light intensities was defined as the contrast, which was used to characterize the surface functionality. The functionality (contrast) of the sample surfaces was evaluated using a microscope as a gonioreflectometer [3] and post processing tools [4].

\subsection{Problem definition}

The optimal dimensions to maximize the contrast are $5^{\circ}$ for ridge angle and $50 \mu \mathrm{m}$ for pitch according to the author's previous work [4]. The contrast generated by the surface was measured within the textured area of $0.8 \times 0.8 \mathrm{~mm}^{2}$. The area, containing 16 micro ridges with the length of $0.8 \mathrm{~mm}$, was defined as one pixel. The height of the micro ridges was approximately 4.4 $\mu \mathrm{m}$. Due to the wear and positioning error of tool, this depth of cut was not able to ensure the tool-sample engagement. Therefore, the depth of cut was increased from $4.4 \mu \mathrm{m}$ to $24.4 \mu \mathrm{m}$. The width of cut was increased by the same proportion, which caused overlapping of the features to achieve the $50 \mu \mathrm{m}$ pitch.

However, a large number of burrs generated in the process and they shielded the working surface that can reflect light effectively. The burr height were correlated with the surface functionality and the tool life was evaluated in our previous work [4]. The increase in the burr height led to the function loss of the surface. Considering the functionality of the surface, the life time of a tool was to machine only 100 pixels, which was too short for industrial applications. A new machining strategy was proposed to reduce the burr formation.

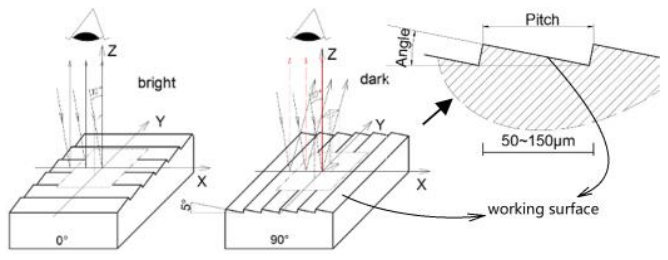

Fig.1. Demonstration of contrast generation of the textured surface and the micro structure.

In order to eliminate the burr formation during the process, it was necessary to understand the mechanism in this experiment. A. Davoudinejad et al. [5] investigated the burr formation in micro end milling with finite element modeling for the prediction of burr generation on the machined wall. The burrs generated in our case were mainly side burrs (down milling side) according to $\mathrm{X}$. Wu and S. A. Niknam $[6,7]$. The most commonly used characterization method of burrs were measuring the morphological dimensions including the height and the width [4-8]. Since the burr formation was subjected to the uncut chip thickness and the thick axial depth of cut $[6,9]$, the increased depth of cut was considered the main sources of burr formation in this study.

\subsection{The machining strategies}

In this study, the process to machine one working surface (one ridge) was defined as one cut.

By the old strategy, down milling was used and the machining order of the ridges was from the top to bottom, as shown by the top left picture of Fig. 2 . From the side view, it could be observed that the width of cut for every ridge was increased as expected. The first cut removed $24.2 \mu \mathrm{m}$ thick material. However, the other cuts removed only 4.4 $\mu \mathrm{m}$ thick material. It was comparable with the radius of the tool cutting edge $(2 \sim 4 \mu \mathrm{m})$. This phenomenal caused ploughing that resulted in tool wear and burrs. 
The tool wear intensified the ploughing sequentially, due to the increasing cutting edge radius. The burrs were indicated in the top left figure of Fig. 2.

By the new strategy, the ridge machining order was reversed while down milling was kept. The material removed for the first ridge was the same as by the old strategy. Then after the first cut, the width of cut was shortened to $49.8 \mu \mathrm{m}$ while the depth of cut kept constant $(24.4 \mu \mathrm{m})$. In this way, by reversing the ridge order, the burrs generated during the previous cut will be removed by the following cut. As a result, no burr was left on the features except the last ridge at the top of a pixel (top right of Fig. 2).

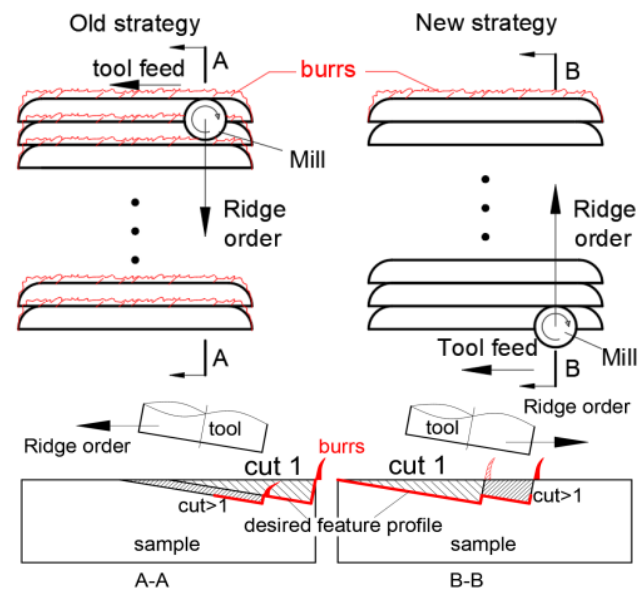

Fig. 2. The old strategy (left) and the new one (right); the red sketches indicate the burrs left on the sample.

\section{Experimental setup}

\subsection{Experimental plans}

A sample as shown in Fig. 3 was machined by applying the new strategy. The material was Orvar Supreme (52 HRC, Uddeholm $\left.{ }^{\circledR}\right)$. The sample consisted of two parts: (1) Z-axial positioning accuracy test: as marked with the dash line box, 100 pixels and 6 reference grooves were machined. The "pixel" was defined in section 1.1.The reference grooves were on a $5^{\circ}$-slope from the sample surface. A new tool was used for each test with the parameters listed in Table 1. This test was conducted to eliminate the influence of the positioning error of the machine on the tool wear test. (2) The tool wear test: 10 blocks containing 100 pixels in each block (marked with the red box in Fig. 3). This test was designed to study the tool wear in order to evaluate the tool life.

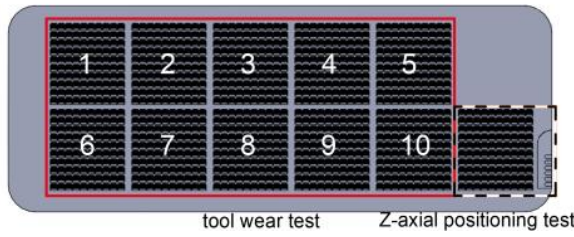

Fig. 3. The layout of the sample.

For the z-axial positioning test, a detailed layout of the features and the tool path were illustrated in Fig. 4. The sample was tilted by $5^{\circ}$ during the machining, which made the "working surfaces" and the grooves perpendicular to the Z-axis of the CNC coordinate.

The reference grooves were $0.5 \mathrm{~mm}$ wide, $1 \mathrm{~mm}$ long and $50 \mu \mathrm{m}$ deep referring to the "zero plane" shown in Fig. 4. The 100 pixels were divided to 5 groups. The features and the reference grooves were machined alternately according to the numbers in Fig. 4. Each reference groove was machined before the corresponding feature group. The groove bottom were the same height as the surface of the first ridge (marked as blue) in the CNC coordinate. The depth differences of the reference grooves were used to track the tool tip position change, i.e. the $\mathrm{Z}$ axial positioning accuracy was obtained by measuring the depth of the 6 reference grooves. The depth of $6^{\text {th }}$ groove indicated the tool tip position after the machining of the $5^{\text {th }}$ group.

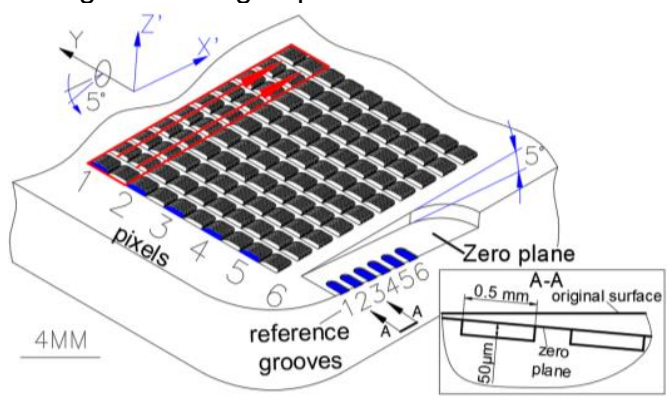

Fig. 4. The $Z$ axial positioning accuracy test.

For the tool wear test, the 10 blocks were machined according to the block numbers in Fig. 3. In each block, the pixels were machined row by row from top to bottom. In each row, the machining order was from left to right.

\subsection{The processing parameters}

The experiments were carried out on a five-axis milling machine (MIKRON HSM 400U LP, control unit: Heidenhain iTNC $530 \mathrm{HSCl}$, measuring probe: builtin). The $\mu$ milling tools were $\mathrm{MXH} 225 \$ 0.5 \times 0.5$ from NS $\mathrm{TOOL}^{\circledR}$. The processing parameters were selected according to the previous work [4]; the processing parameters and the tool specifications were listed in the Table 1.

Table 1.

The tool specifications and the milling parameters.

\begin{tabular}{|c|c|c|c|}
\hline Tool specificatio & ons & Milling param & eters \\
\hline Diameter & $0.5 \mathrm{~mm}$ & Spindle speed & 40000rpm \\
\hline Material & ain carbide & e Tool tilting & $5^{\circ}$ \\
\hline Coating & TiAIN & Coolant & Oil + air \\
\hline Helix angle & $25^{\circ}$ & Feed rate & $800 \mathrm{~mm} / \mathrm{min}$ \\
\hline Number of flutes & 2 & Feed per tooth & $0.01 \mathrm{~mm}$ \\
\hline Relief angle & $8^{\circ}$ & Width of cut & $49.8 \mu \mathrm{m}$ \\
\hline Flute length & $0.5 \mathrm{~mm}$ & Depth of cut & $24.4 \mu \mathrm{m}$ \\
\hline Cutting edge radis & lius $2 \sim 4$ & & \\
\hline
\end{tabular}

\subsection{The surface evaluation}

The surface quality was highly associated with the tool wear. During the process, the tool tips lost material of a triangular shape as the red marks in Fig. 5 (a). An enlarged tool tip in Fig. 5 (a) showed how the tool wear determined the feature geometry: the ridge height, the ridge width and the groove angle. The groove angle was defined by two slopes of two neighbour ridges. Fig. 5 (b) illustrated the definition of the dimensions of the actual features. Since the tool 
length was from the tool head to the tips, the tool became shorter when it wore, which decreased the feature depth. The tool wear also increased the surface roughness and the burr formation.

These parameters were analysed to characterize the feature quality and to reveal the development of tool wear. The sample was scanned by a laser confocal microscope with the magnification of 50X. The geometrical features were measured by postprocessing the images in the software SPIP ${ }^{\circledR}$. Every $100^{\text {th }}$ pixel was measured to find the influence trends of tool wear on these parameters.

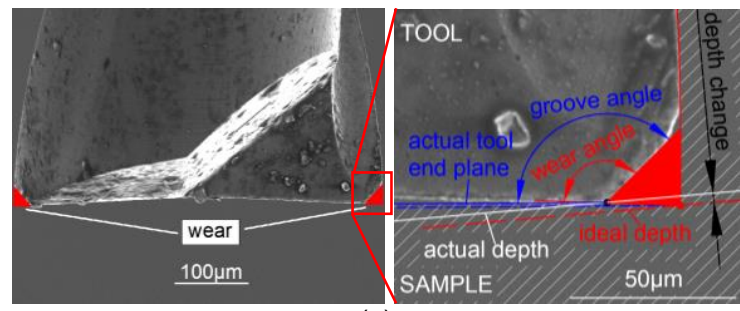

(a)

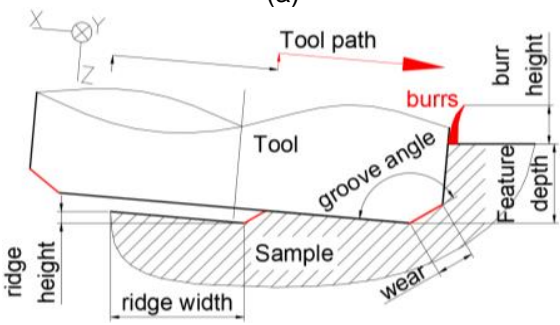

(b)

Fig. 5. The worn tool from SEM (a) and the definitions of the feature dimensions $(b)$

\section{Results and analysis}

\subsection{The comparison of two strategies by inspecting surface geometries}

Comparing the feature geometries produced by the two strategies revealed how the new strategy improved the surface quality. The central area of each pixel was scanned.

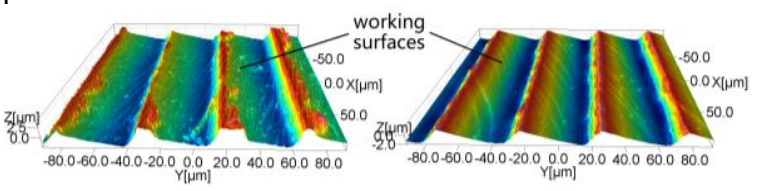

(a)

(b)

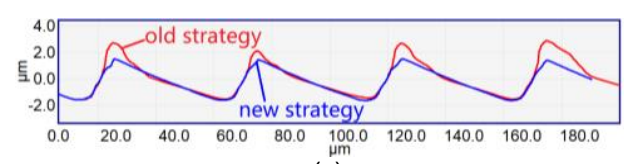

(c)

Fig. 6. The comparison of the geometries of (a) features by old strategy and (b) features by new strategy; (c) the comparison of the average profiles.

Fig. 6 shows the topographies and the average profiles of the $100^{\text {th }}$ pixel by both strategies. (a) shows lot of burrs left on the features produced by the old strategy. (b) shows no burrs were left on the features by new machining strategy. Further measurements proved that no burrs formed even after machining 1000 pixels. As expected, the burrs were only observed on the last ridge of each pixel.

\subsection{The $Z$ axial positioning accuracy}

The 20X lens was used in the measurements of the groove depth and the results were illustrated in the Fig. 7. The nominal depth was $50 \mu \mathrm{m}$, which was indicated by the dark red line. The tool tip position changed after machining 20 pixels while all the grooves were deeper than $50 \mu \mathrm{m}$. However, there was a rising tendency of the tool position as the processing progressed (the blue dash line).

Considering the machining and the measuring condition, the resultant tool positioning accuracy was $3.42 \pm 1.1 \mu \mathrm{m}$ with an increasing trend of tool position on Z-axis. The results were used to guide the followup experiments as the reference of manual compensations for the depth of cut.

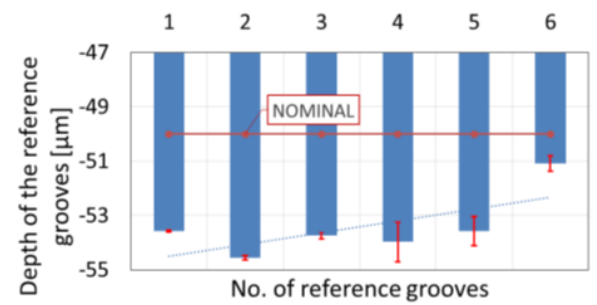

Fig. 7. The depth of the reference grooves indicating the $z$ axis positioning accuracy.

\subsection{Tool wear evaluation}

The tool wear were evaluated by measuring the surface roughness and geometrical dimensions shown in Fig. 5 (b).

\subsubsection{Surface roughness}

The surface roughness (Sa) were measured on 5 working surfaces in every $100^{\text {th }}$ pixel obtained from the LEXT as shown in Fig. 6 (a) and (b). As plotted in Fig. 8, an increasing trend of surface roughness was observed: Sa increased from $49.96 \mathrm{~nm}$ to $96.66 \mathrm{~nm}$ over 1000 pixels. The roughness was relatively stable among the first 400 pixels and fluctuations emerged after that. The trend can be associated with the tool wear, which will be verified by further tool wear tests.

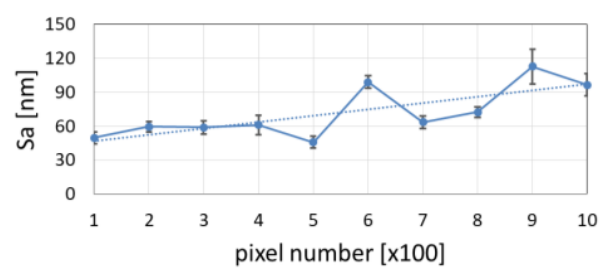

Fig. 8. The roughness of the working surfaces grew along with the process.

\subsubsection{Burr heights and feature depths}

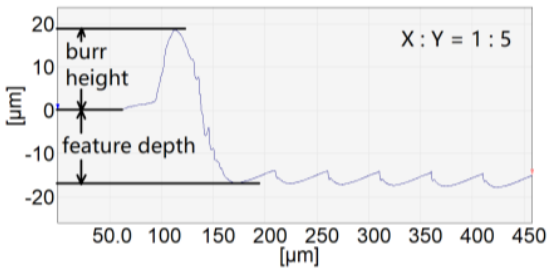


Fig. 9. The measurements of burr height and feature depth on the profile of the $480^{\text {th }}$ pixel.

The height of the burrs and the feature depth was defined based on the original surface of the sample, which was illustrated in Fig 5 (b). As an example, Fig. 9 shows the measurements on the profile of the $480^{\text {th }}$ pixel. As the burrs could only be found on the last cut, the top area of the pixels were scanned and analysed.

Fig. 10 shows the trends of the burr height and feature depth against the pixel number. The burr height grew stably along with the pixel numbers, except a protrusion on the $6^{\text {th }}$ block. The depth of the features increased slightly among each 5 blocks on the sample, which verified the analysis of tool top position change in section 3.2.

However, between the $5^{\text {th }}$ and the $6^{\text {th }}$ block, there were a decrease in the feature depth and a steep rise in surface roughness and burr height. The possible reasons could be the accumulating tool wear, tool tip crack, $X / Y$ positioning error and uneven hardness of the sample surface, which will be investigated in the future experiments.

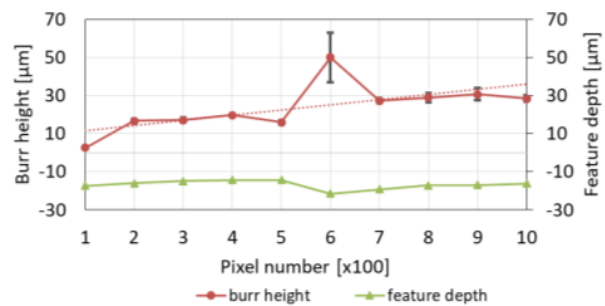

Fig. 10. The burr height and feature depth changed in the process.

\subsubsection{Feature dimensions}

The tool tips ended up with a triangular shaped wear from the side view (shown in Fig. 5). Fig. 11 showed linear trends of the three parameters, with zig-zag fluctuations, against the pixels numbers: the ridge height and the slope width decreased while the groove angle increased. Moreover, the slope width decreased with respect to the feature height, which resulted in the increase of the feature groove angle. After 1000 pixel machining, the changes in the ridge height, the ridge width and the groove angle were $1.17 \mu \mathrm{m},-0.61 \mu \mathrm{m}$ and $15.74^{\circ}$, respectively.

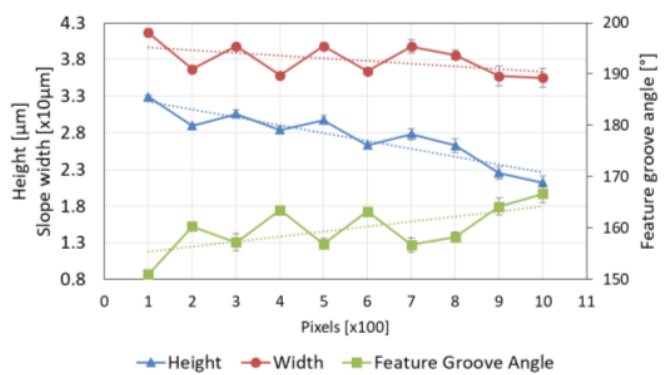

Fig. 11. The geometry dimensions changed with the pixels.

The feature dimensions were determined by the tool tip shape. Therefore, the changes in the dimensions could reveal the tool wear development: the wear angle increased as the groove angle of the features; the wear length increased as the width and the height of the working surfaces decreased. Furthermore, since the slope width determines the area of the working surface, the decreasing of the reflection could be expected, which will be verified by function tests in the follow-up research.

\section{Conclusions}

The micro milling strategy has been studied to reduce the burr formation. The new strategy was proved to better than the old one. The features produced by the old strategy were mostly shielded by burrs after 200 pixels. By the new strategy, no obvious burr was found in the 1000 pixels except the last cut.

This method is suitable for manufacturing such micro-structured surfaces with optical functionality. After machining 1000 pixels, the roughness (Sa) of the working surfaces increased slowly from $50 \mathrm{~nm}$ to $96.66 \mathrm{~nm}$ and the width of the working surfaces decreased by $0.61 \mu \mathrm{m}$. That ensured enough amount of effective working surfaces for the parts to achieve the function. By the old strategy Due to the burrs, it was impossible to produce so many effective working surfaces. Thus, the tool life was improved when considering the surface function.

In the future work, the functionality assessment and the study on tool wear propagation will be dedicated to make accurate predictions of the tool life. The finding of this investigation will be applied to the future experiments.

\section{Acknowledgements}

This paper reports work undertaken in the context of project 5163-00001B funded by Innovation Fund Denmark. The project is partially sponsored by the China Scholarship Council (CSC).

\section{References}

[1] A. Malshe et al., "Bio-inspired functional surfaces for advanced applications," J. CIRP Annals Manufacturing Technology. 2013; 62(2): 607-628.

[2] R. S. Eriksen et al., "Manufacture of functional surfaces through combined application of tool manufacturing processes and Robot Assisted Polishing," J. CIRP Annals - Manufacturing Technology, 2012; 61(1): 563-566

[3] S. Nevas et al., "Gonioreflectometer for measuring spectral diffuse reflectance," J. Applied Optics, 2004; 43.35: 6391-6399.

[4] D. Li et al., "Evaluation of Optical Functional Surfaces on the Injection Moulding Insert by Micro Milling Process," Proceedings of the Euspen Special Interest Group Meeting, 2017.

[5] A. Davoudinejad et al., "Influence of the worn tool affected by built-up edge (BUE) on micro endmilling process performance: A 3D finite element modeling investigation," J. Precision Engineering and Manufacturing, 2017; 18(10): 1321-1332.

[6] $X$. Wu et al., "Investigation on the burr formation mechanism in micro cutting," J. Precision Engineering, 2017; 47: 191-196.

[7] S. A. Niknam et al., "Analysis of friction and burr formation in slot milling," Procedia CIRP, 2014; 17: 755-759.

[8] P. Kumar, et al., "Recent advances in characterization, modeling and control of burr formation in micro-milling," Manufacturing Letters, 2017; 13: 1-5.

[9] M. J. Chen, et al. "Research on the modeling 
of burr formation process in micro-ball end milling operation on Ti-6Al-4V," J. Advanced Manufacturing Technology, 2012; 62.9-12: 901-912. 